\title{
La perspectiva ética levinasiana: su sentido para la educación
}

\author{
Alfredo Rocha de la Torre ${ }^{1}$ (1) \\ Universidad Pedagógica y Tecnológica de Colombia, Colombia
}

A la memoria de Alejandra Rangel Hinojosa, amiga en el desierto que crece

Autor de correspondencia: ${ }^{1}$ rochtorre@yahoo.com Recibido: 15 de junio de 2020 Revisado: 30 julio de 2020 Aprobado: 31 de octubre de 2020 Publicado: 26 de enero de 2021

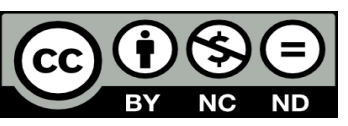

\section{Resumen}

Este artículo busca señalar el vínculo entre la filosofía de Emmanuel Lévinas y la educación - $\pi$ aı $\delta \varepsilon i ́ a-$. Al tomar distancia de intentos de aplicación axiológica y deontológica de la ética levinasiana en la educación, se sostiene que más allá de instrumentalizar las categorías fundamentales del pensador lituano, se trata de comprender el sentido de su filosofía y la forma como este puede enriquecer la praxis pedagógica. El trabajo se desarrolla en seis pasos: (1) caracterización de la filosofía levinasiana como descentramiento de la subjetividad y de su preeminencia ética; (2) descripción de dos ámbitos de la experiencia humana - gozo y Deseo-, que marcan (3) dos tipos diversos de educación: para la alimentación y para la responsabilidad hacia el Otro; (4) caracterización del mundo actual como mundo del trabajo, del cálculo, de la habilidad y de la relación de medios y fines, en el que (5) los ámbitos de aparición de un tercero - política, economía, justicia, educaciónpretenden degradar la ética a un segundo plano; y (6) la necesidad de poner el rostro del Otro como centro del acto educativo.

Palabras clave: ética, educación, responsabilidad, rostro, Otro 


\title{
Levinas' ethical perspective: its meaning for education
}

\begin{abstract}
This paper seeks to outline the link between the philosophy of Emmanuel Levinas and education- $\pi \alpha i \delta \varepsilon i \alpha$. By taking a distance from attempts to apply the axiological and deontological aspects of Levinas' ethics in education, it is argued that, beyond instrumentalizing the fundamental categories of the Lithuanian thinker, it is a matter of understanding the meaning of his philosophy and how this can enrich pedagogical practice. The work is carried out in six steps: (1) characterization of Levianasian philosophy as a decentralization of subjectivity and its ethical pre-eminence; (2) description of two areas of human experience-enjoyment and Desire-which define (3) two different types of education: for nourishment and for responsibility towards the Other; 4) characterization of today's world as a world of work, of calculation, of skill and of the relation between means and ends, in which (5) the areas of emergence of a third party-politics, economics, justice, education - are intended to degrade ethics to a second level; and (6) the need to place the face of the Other at the center of the educational act.
\end{abstract}

Keywords: ethics, education, responsibility, face, Other.

\section{A perspectiva ética levinasiana: seu significado para a educação}

\section{Resumo}

Este artigo procura apontar a ligação entre a filosofia de Emmanuel Levinas e a educação

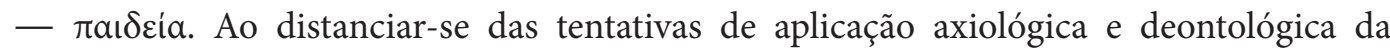
ética levinasiana na educação, argumenta-se que, além de instrumentalizar as categorias fundamentais do pensador lituano, trata-se de compreender o sentido de sua filosofia e a forma como pode enriquecer a práxis pedagógica. $O$ trabalho é desenvolvido em seis etapas: (1) caracterização da filosofia de Levinas como descentralização da subjetividade e da sua preeminência ética; (2) descrição de duas esferas da experiência humana - gozo e Desejo - que marcam (3) dois tipos distintos de educação: para a alimentação e para a responsabilidade com o Outro; (4) caracterização do mundo atual como um mundo de trabalho, de cálculo, da habilidade e da relação de meios e fins, em que (5) as áreas de emergência de um terceiro - política, economia, justiça, educação - pretendem degradar a ética para um segundo nível; e 6) a necessidade de colocar o rosto do Outro como centro do ato educativo.

Palavras-chave: ética, educação, responsabilidade, rosto, Outro 
La afirmación levinasiana de que la ética es filosofía primera ${ }^{1}$ se ha convertido en un hito del pensamiento occidental. Pero es un hito no solamente por el hecho de haber puesto en lo más alto de la discusión filosófica contemporánea la problemática ética, sino también por llevar a cabo un descentramiento del eje subjetivista de la reflexión habida hasta el momento y por postular al Otro como génesis de la relación humana². Basado en su posición crítica respecto al carácter abarcador de los sistemas filosóficos de Occidente, Lévinas resalta el rasgo primigenio del hecho ético y la esencia de este en la socialidad ${ }^{3}$, cuyo fundamento no puede ser otro que la revelación del rostro4 (Lévinas, 1991) y la asunción de la responsabilidad por parte del Mismo.

Es precisamente esta diada conceptual -descentramiento de la subjetividad y preeminencia ética - la que sirve de base a una reflexión acerca de las implicaciones de la filosofía de Lévinas en la educación, considerada como formación (Jäger, 2002). No se trata, sin embargo, de una meditación en torno a las aplicaciones de la propuesta levinasiana en la enseñanza de la ética ni de la búsqueda de estrategias para el adiestramiento de estudiantes en las competencias ciudadanas requeridas para su óptima inserción en la sociedad. Se trata de reflexionar, por el contrario, en torno al sentido que la interpretación de la ética en Lévinas puede aportar a la educación.

Pero este sentido no será significativo si no es pensado en el marco de la relación de esta perspectiva ética con la política y, de manera indirecta, con la economía y la cultura actuales. El vínculo que se puede establecer entre la concepción levinasiana y la educación, en el contexto de una cultura en la que prima el plano económico de apropiación y consumo del mundo natural, permite postular el significado de la educación en dos vertientes: (a) aquella que predomina en el mundo actual y que, surgida con la revolución industrial, está centrada en la preparación de las habilidades y destrezas necesarias para el trabajo, incluyendo, por supuesto, toda la policromía de éticas deontológicas que sirven de apoyo al buen desempeño laboral y, (b) aquella pensada desde la ética de la alteridad y su exigencia de responsabilidad para con el Otro.

La primera de estas opciones será considerada como una "educación centrada en el gozo", es decir, como una educación que prepara exclusivamente "para la alimentación", para consumir eficientemente. La segunda posibilidad es concebida en términos de formación $-\pi \alpha i \delta \varepsilon i \alpha-$ en la sensibilidad para con el Otro y, en este sentido, como una educación a la que le es esencial la ética entendida en clave levinasiana.

Aunque Lévinas no desarrolló explícitamente la relación entre su perspectiva ética y la educación, su propuesta posibilita otorgar un rol preponderante a la ética en el proceso educativo, como alternativa a la consideración de la educación como simple instrumento

\footnotetext{
1 Contra la concepción aristotélica de la metafísica como ontología y filosofía primera - $\pi \rho \omega ́ \tau \eta \varphi \imath \lambda o \sigma o \varphi \alpha_{\alpha}-($ Aristóteles, 1990), Lévinas otorga este carácter a la ética. De la centración aristotélica en el ente en cuanto ente, se dará el paso a la primacía del Otro en tanto rostro (Critchley, 2005; Lévinas, 1987a, 1991, 2006a).

2 Lévinas no pretende negar la subjetividad, sino reevaluar su constitución y estatuto. De la subjetividad considerada en términos de subjectum dador de sentido, Lévinas pasa a la subjetividad constituida en la responsabilidad para con el Otro.

3 El control ético sobre la esfera social y política funda lo que Lévinas denomina "segunda forma de socialidad", para diferenciarla de la simple relación social sin mediación de la esfera ética (1991, 1987a).

4 Solo como revelación —révélation - es posible el discurso del rostro, ya que como develación — dévoilement- o descubrimiento — découverte- no sería más que un fenómeno ante los ojos de un sujeto que lo integraría a sí mismo en forma de percepción o de idea; sería una simple relación de un sujeto cognoscente con un objeto.
} 
del aprendizaje de habilidades o competencias para el trabajo y para la adaptación a los requerimientos del sistema socioeconómico dominante en el mundo contemporáneo.

El papel de la ética en el proceso educativo no se limita a la enseñanza de reglas de acción para la convivencia, una especie de pedagogía del trato con los Otros — pretensión ya señalada como insuficiente por Aristóteles $(1995)^{5}$ - , sino que consiste en dar prioridad a una formación descentrada de la concepción del mundo social y natural como simple objeto de apropiación y usufructo. La concepción de la alteridad como exclusivo objeto de consumo es lo que Lévinas identifica como el ámbito del gozo - jouissance- y de la alimentación, concebida como incorporación de lo otro en mí: apoderamiento de la alteridad a través de la asimilación fruto de la representación, de la percepción o de la simple ingestión física del mundo natural.

Se trata, entonces, de ir más allá de una simple pedagogía centrada en valores, o fundada en la intención de hacer de la ética un instrumento de enseñanza para la vida en sociedad, como parece ser el caso de algunas propuestas pedagógicas que buscan reivindicar la perspectiva levinasiana en la escuela. Este es el caso de algunas tendencias de usar la ética levinasiana como herramienta social que debería jugar un rol preponderante en la educación, en el marco del énfasis actual sobre la enseñanza y fortalecimiento de las competencias en ciencias básicas(Jaramillo et al., 2018; Mínguez, 2010; Romero \& Pérez, 2012).

Si bien el contexto de la educación contemporánea está caracterizado por esta primacía de la capacitación en habilidades científicas y tecnológicas - objetivo del fortalecimiento de las competencias anteriormente referidas-, varias son las razones que permiten calificar como desacertado el intento de aplicar las categorías filosóficas del pensador lituano con el ánimo de postular "otra educación" guiada por principios éticos, de alguna manera "enfrentada" a la atmósfera escolar en la que se presta mayor importancia a la "formación" para el trabajo y el desarrollo económico. Entre dichas razones están:

a) La confrontación que se puede establecer entre conocimiento científico y otro tipo de conocimiento, en el que parece estar integrada la ética, no compagina con una propuesta en la que la relación ética no pertenece al plano gnoseológico y, por tanto, no es equiparable, ni siquiera por oposición, a algún tipo de conocimiento 6 . Para Lévinas - y esta es la razón de su oposición a considerar la ética como un tipo específico de saber-, todo conocimiento es la expresión del modo en que un sujeto integra el mundo en sí, es decir, la manera como se comprehende la alteridad en mí a través de la representación, lo que negaría e imposibilitaría la revelación del Otro en tanto trascendencia, que es lo que finalmente caracteriza su propuesta ética (Lévinas, 1987a).

b) Dejar abierta la posibilidad de que la ética pueda ser considerada como un "contenido educativo", va en contravía del distanciamiento levinasiano ante toda forma de explicación de la relación primigenia humana a partir de un sistema que

\footnotetext{
5 Lévinas tampoco concibe que la ética derive de un proceso formativo, pero difiere de Aristóteles por lo menos en tres aspectos: (a) en la concepción de la ética como virtud, (b) en la derivación de tal virtud en la costumbre y (c) en el carácter político de la ética.

6 Aunque Lévinas utiliza el término "conocimiento" cuando trata del modo como el Otro se revela, no lo considera como fruto de la percepción o de la representación, procesos propios de la integración de lo Otro en mí (Lévinas, 1987a).
} 
la abarque; en este caso, aquel sistema que configura un conjunto de saberes que pueden ser objeto de enseñanza y aprendizaje y, con ello, parte de un todo que le otorga su sentido. La ética, concebida en términos de relación-religare- cara a cara, no es objeto de instrucción (Lévinas, 1991), como tampoco de formación en el sentido común, sino que es el fruto de una "imposición", de una orden que emana de la revelación del Otro: "El rostro me pide y me ordena. Su significación es una orden significada. [...] esa orden es la significancia misma del rostro" (Lévinas, 1991, p. 92). "El rostro significa el Infinito. Este nunca aparece como tema, sino en esta misma significancia ética" (p. 97). "El testimonio ético es una revelación que no es un conocimiento" (p. 101).

c) Se hace evidente, entonces, que el rol de la ética en la educación no puede ser identificado con la formación en valores, tal como puede apreciarse en las propuestas de Romero y Pérez (2012) y de Mínguez (2010).

Una conversión de la perspectiva ética de Lévinas en un conocimiento más que puede ser impartido en clase y como un contenido educativo con programa y metodología propia para ser enseñado, así como la interpretación de sus conceptos fundamentales — verbigracia "la responsabilidad" - en términos de valores (Romero \& Pérez, 2012), tiende a caer en la instrumentalización de una lectura filosófica que busca reflexionar en torno a un "absoluto" ético, más allá de la validación siempre relativa de la cultura, la sociedad y el individuo. "Responsabilidad" - al igual que "rostro"-, por ejemplo, no es una noción instrumental aplicable en el proceso de enseñanza-aprendizaje, como si de un contenido particular se tratara. Es un concepto de carácter metafísico que, al no estar restringido a su significado legal, psicológico o moral, no puede ser considerado en términos de conocimiento objeto de instrucción, ni de habilidad, competencia o valor proclive a ser formado. Esta es la razón por la cual Lévinas sostiene que incluso sin que lleguemos a ser responsables en una situación particular ante un hombre determinado, somos responsables como respuesta a una orden emanada de la simple revelación del Otro en tanto rostro. Por ello concluye que la "responsabilidad" no es un mero aderezo de la subjetividad (Lévinas, 1991).

Es posible, por lo tanto, afirmar que la pregunta por la relación entre ética y educación no se responde a través de su instrumentalización —al sopesar sus posibles usos o funciones pedagógica, social, psicológica, entre otras-, sino en la dilucidación del sentido de la ética en la formación del hombre, en el marco de la sobrevaloración actual del plano económico del gozo sobre el ámbito ético de la responsabilidad (Lévinas, 1991,1987b).

\section{La ética en Lévinas - generalidades-}

La ética de Lévinas es una crítica acérrima a la tradición filosófica de Occidente, en lo que concierne especialmente al énfasis de esta sobre la subjetividad dadora de sentido. La concepción cartesiana del sujeto concebido como subjectum — substrato-, como fundamento de todo lo que es (Descartes, 2011a, 2011b), abarca no solamente las concepciones filosóficas deudoras directas del pensador francés y su perspectiva idealista, sino también todas aquellas acepciones fundadas, implícita o explícitamente, en un substrato que otorga significado a todo aquello que se encuentra enfrente - vor-stellt-. Para Lévinas, la historia de la filosofía está caracterizada, entonces, por la primacía de la 
"mirada" fundante del Mismo, no obstante sus diversas acepciones sobre lo Otro?.

Esta misma estructura básica de la relación del hombre con "lo Otro" es la que en general determina la relación del Mismo con "el Otro" a lo largo de la tradición filosófica occidental: el Otro constituido desde la percepción, la representación, la interpretación del Mismo. Es ante esta estructura explicativa de la relación entre los hombres que Lévinas toma distancia de la tradición ética occidental, para plantear su propuesta de una ética centrada en el Otro. El Otro, concebido en términos de trascendencia e infinito, es la base de toda posibilidad de una auténtica relación entre los hombres, más allá del simple vínculo fundado en el ámbito económico en el que impera el gozo.

Al tomar distancia del origen ontológico de la filosofía con Platón y Aristóteles ${ }^{8}$, Lévinas (1987a) tiene una actitud crítica ante el concepto de ser, que llegó a su culmen, según él, con la ontología fundamental heideggeriana', a la que fustiga por considerarla indiferente al hombre y a la pregunta ética por el Otro. Toma distancia de la ontología y de toda filosofía en la que el sujeto sea concebido como fundamento donador de sentido. Estos son dos de los rasgos más sobresalientes de la filosofía del pensador lituano. Algunos otros rasgos de la perspectiva ética levinasiana son:

\section{La concepción de una ética no normativa}

Lévinas no postula una moral de carácter deontológico, preocupada por el establecimiento de un código de acción que explicite valores u obligaciones específicos a seguir. Dado el carácter estructural del tipo de relación auténticamente humana señalada por Lévinas, es viable afirmar que a diferencia de la definición acostumbrada de la moral como teoría del "deber ser", la perspectiva levinasiana no es concebida como canon de la praxis humana, sino que se configura como una "mostración" de la esencia de la relación ética; como descripción de la estructura inherente y constitutiva del modo en que el Mismo acoge la interpelación del Otro.

Un ejemplo de este carácter sui generis de la ética levinasiana es el concepto de "responsabilidad", que por principio no es una noción jurídica — responsum - que implique la existencia de un sujeto que responda social, política y legalmente por sus acciones, en el contexto de la adecuación de estas normas establecidas por un orden jurídico determinado. Tampoco hace referencia a una responsabilidad moral que suponga una subjetividad soberana, que en su libre decisión lleve a cabo acciones objeto de encomio o crítica y censura en el marco de una concepción moral determinada.

La "responsabilidad" no es, por lo tanto, una posición activa del sujeto frente a sus acciones - y con ello frente a la sociedad, la justicia y la cultura-, sino el recibimiento pasivo de una orden emanada del rostro del Otro en su revelación y, de esta manera, nada más que una imposición más allá del querer y el libre albedrío del sujeto. Contraria a lo que

$7 \quad$ Lévinas hace uso del término "Otro" en por lo menos tres sentidos: (1) "Lo Otro", que incluye la alteridad del hombre y el carácter objetual de lo que está frente a mí; (2) "Lo otro" en tanto objeto; 3) y "El Otro", que designa la alteridad en su acepción ética.

8 Lévinas concibe que la metafísica en tanto ontología se caracteriza por su olvido del hombre, o por la subordinación de este a una totalidad impersonal que lo englobará bajo sus categorías. Basado en esta consideración, emprende una fuerte crítica a Heidegger (Lévinas, 1987a, 1993a, 2000). Una lectura distanciada de dicha crítica puede verse en Rocha (2014).

9 En contra de la ontología, Lévinas (1987a) sostiene que esta es una filosofía del poder y de la injusticia, que lleva a la tiranía. 
las definiciones jurídica y moral ya señaladas implican — una subjetividad libre y activa en tanto subjectum-, la lectura levinasiana resalta el carácter pasivo y no voluntario de la "responsabilidad" ética: no se trata de una decisión para "hacerse responsable de..." o de la realización de una acción evaluada según su nivel de adecuación a la norma establecida, sino del "recibimiento" de una imposición no violenta que la simple "presencia" del otro genera en mí.

La responsabilidad no tiene, entonces, su origen en el libre arbitrio de un sujeto que otorga sentido a todo lo que es, sino que configura la constitución misma del sujeto en la revelación del Otro: "soy yo en la sola medida en que soy responsable [...] Tal es mi identidad inalienable de sujeto" (Lévinas, 1991, p. 96). Es por esta razón que no podemos sostener que decidimos ser responsables ante el Otro, sino que somos responsables solo y exclusivamente gracias a él.

\section{El establecimiento de dos ámbitos de la existencia humana}

El punto de partida de Lévinas en Totalidad e infinito (1987a) es la consideración de dos ámbitos en la existencia humana: el ámbito del gozo egoísta y el ámbito del Deseo (1987b).

El primero de estos ámbitos está centrado en el aspecto económico de la vida humana, en el que predomina la búsqueda de la satisfacción de las necesidades y el gozo individual propio del egoísmo del hombre centrado en sí mismo. La metáfora usada por Lévinas para referirse a esta experiencia —en la que convergen "satisfacción y gozo del mundo" y el "egoísmo" propio del Mismo centrado en sí- es la alimentación — la nourriture - Gozo, egoísmo y alimentación coinciden en la experiencia de la incorporación de lo Otro al Mismo, en la que lo Otro se convierte en parte del Mismo: deviene "Mismo". Esto es obvio, por ejemplo, en el proceso digestivo del animal, al momento de la ingesta de sus alimentos, convertidos a causa del mencionado proceso en parte constitutiva de quien los consume. Esta metáfora se puede aplicar también a otros modos de integrar el mundo en mí, como, por ejemplo, en la constitución de una idea a través de la representación de un ente pensado, o en la interiorización de una ideología explicativa del mundo natural, político, económico, social o cultural (Lévinas, 1987a).

La tercera expresión metafórica de la alimentación — la ideológica - puede ser considerada como una forma muy peligrosa de integrar el mundo en mí, ya que consiste en negar la trascendencia y la carencia de forma del Rostro, para explicarlo y, de esta manera, apresarlo, a partir de criterios previamente establecidos por una construcción subjetiva. Es por ello que el totalitarismo político y el cultural pueden ser entendidos a partir de esta metáfora de la alimentación del hombre constantemente insatisfecho: son la manifestación de la insaciabilidad posesiva del gozo permanentemente incumplido.

Ante esta tendencia del hombre dominado por el gozo, que siempre es la manifestación de un "para mí egoísta", de un impulso de apropiarse del mundo y consumirlo, Lévinas (1987a, 1991) plantea la experiencia —Erfahrung - del "para el Otro", que es originaria y simultáneamente fundante de la relación ética en tanto respuesta a la interpelación del Otro. El rostro será considerado, en consecuencia, como la entrada ética a una experiencia caracterizada por el descentramiento del "Mismo", que rompe con la constitución de mi propia vivencia - Erlebnis - como ente fundante del sentido de la alteridad humana ${ }^{10}$.

$\overline{10}$ En este principio está basada la crítica levinasiana al carácter constituyente de la representación (Bernasconi et al., 1996; 
Para evitar todo tipo de "ideologización del rostro" — es decir, de explicación o interpretación de este a partir de categorías explicativas establecidas por la subjetividady con ello evitar su determinación como algo cargado de significación social, política, cultural..., Lévinas (1987a, 1991, 2009; Critchley, 2005) señala el carácter no accesible del rostro a la actividad perceptiva o representativa del hombre. Esto quiere decir que la esencia del rostro no es de naturaleza física, y por ello no puede ser fijado a través de los sentidos humanos ni de la capacidad del hombre para transformar su entorno en ideas a través de la raepresentatio. En su acepción ética, el rostro no está constituido, entonces, como "forma" ni "figura"; no posee contornos que permitan aprehenderlo como un simple ente cualquiera que comparece ante "mi mirada" (Lévinas, 2000, p. 51).

La afirmación de que el rostro no se reduce a percepción, conocimiento o representación implica que debe ser entendido en términos de "expresión sin contexto" (Lévinas, 1991, p. 80), ya que el contexto supone una diversidad de formas que distinguen y dividen al hombre a partir de sus diferencias, facilitan su objetivación y pueden conducir irremediablemente hacia la discriminación: se es blanco o afrodescendiente, hombre o mujer, de izquierda o de derecha, de una región determinada de un país, con una historia particular, creyente o ateo... Esta objetivación a partir de la figura y la forma específica en que se presenta el hombre ante la mirada de los demás abre la posibilidad de que cada ser humano sea objeto de aceptación o rechazo según su origen, su raza, su procedencia, su ideología o credo, a partir de la preconcepción de quien como sujeto hace las veces de fundador del sentido.

Esta concepción metafísica del rostro ${ }^{12}$ permite, en consecuencia, sostener que la base ontológico-constitutiva de la guerra, la discriminación y la violencia en general ${ }^{13}$ es dual: la constitución del sujeto como entidad instituyente de sentido y la consideración del Otro como poseedor de una forma, como portador de un contexto que lo determina ante los ojos de quien lo representa, lo mira, lo interpreta; en otras palabras, ante la mirada de quien lo conoce y lo explica.

Con este marco de referencia, Lévinas (1987a) concibe que la experiencia irreductible de la relación ética no está fundada en la síntesis fruto de la constitución de la figura del Otro desde mí, sino que es la relación del cara a cara en su significación moral, es decir, aquella relación que parte de la revelación del rostro del Otro: no se trata ahora de la subjetividad encapsulada en forma de "para-si" que explica el mundo, sino de un sujeto constituido "para el Otro" en el acatamiento no voluntario de una responsabilidad constitutiva y estructural. Por eso, el filósofo afirma que la primera "palabra" del rostro es el "no matarás" convertido en orden moral (Lévinas, 1987a, 1991, 1993a, 2006b; Critchley, 2005).

El Otro como tal es, entonces, trascendencia, es decir, Deseo - Désir — que se acrecienta sin nunca ser colmado. De manera sustancialmente diferente al gozo - que se apropia de un objeto externo en la alimentación o que aprehende al mundo y lo Otro a través del

Critchley, 2005; Lévinas, 1987a, 1993b, 2017).

11 Ideología: ideas encadenadas entre sí con el objetivo de explicar el "rostro" o dar razón de él. Esto implica la generación de interpretaciones, presuposiciones y asignaciones de valor, que harían perder al rostro su desnudez para convertirlo en una simple forma cargada de significados y, por ende, en objeto alcanzable por los sentidos y la conciencia.

12 Contrario a la concepción tradicional de la metafísica como ontología, Lévinas (1987a) concibe su filosofía como metafísica centrada en el Otro en tanto trascendente a todo intento de aprehensión (Bernasconi et al., 1996).

13 Respecto al sustento ontológico de la guerra, que implica la suspensión ética (Lévinas, 1987a, 2006b; Mosès, 2004). 
conocimiento propiciado en la percepción, la representación y la interpretación, y mediante estas incorpora lo Otro en sí como posesión-, el Deseo trata con lo inaprehensible, que no es objeto de alimentación en ninguna de sus formas posibles (Lévinas, 1987a).

El rostro del Otro, en tanto trascendencia imposible de ser englobada y apresada bajo categorías del conocimiento, se configura de esta manera en expresión del Infinito (Lévinas, 1987a $)^{14}$. El sujeto - testigo que da testimonio de este Infinito, es decir, como pasividad que se abre a la revelación del Infinito - es simultáneamente testimonio de sí mismo en la responsabilidad que lo constituye como un ser para el Otro (Lévinas, 1991).

\section{El lugar de la política en Lévinas}

¿Pero qué tiene que ver la ética con la política y la educación? ¿Cómo pensar estos dos ámbitos de la experiencia humana a partir de la reflexión centrada en la ética? Lévinas (1987a) entra al ámbito de la política a través del concepto de justicia. Su objetivo no es, sin embargo, llevar a cabo una discusión en el campo de la filosofía política acerca del concepto en mención, sino delinear el modo en que se desarrollan las relaciones humanas determinadas bajo el prisma de este concepto, en el marco de la experiencia ética concebida como responsabilidad para con el Otro.

Mientras que la relación ética tiene como origen la revelación del Otro en tanto rostro y la recepción pasiva que de este hace el Mismo — quien, en palabras de Lévinas, pierde de esta manera su imperialismo (1987a, 2009) - , la justicia y la política se configuran a partir de la aparición de un tercero que introduce una novedad en la relación del encuentro cara a cara. Esta novedad consiste en la "desviación" del primado del Otro hacia el primado del conjunto social, que directa o indirectamente conduce a planos abstractos, generales y "despersonalizados", como la economía, la política partidaria y la legalidad, entre otros. Todo esto es visto por Lévinas (1987a) no solamente como un espacio de interacción entre los hombres - diferente a la relación primigenia del Mismo con el Otro-, sino también como una posibilidad del despliegue del poder y de la guerra ${ }^{15}$. Esta es la razón por la cual el filósofo enfatiza en la necesidad del control ético sobre el ámbito de la política y la justicia: "En efecto, la política debe poder ser siempre controlada y criticada a partir de la ética" (Lévinas, 1991, pp. 76-77).

La relación interpersonal que establezco con el otro debo también establecerla con los otros hombres; existe, pues la necesidad de moderar ese privilegio del otro; de ahí, la justicia. Esta, ejercida por las instituciones, que son inevitables, debe estar siempre controlada por la relación interpersonal inicial. (p. 84)

Este proceder de control ético sobre la política y la justicia puede ser extendido a todos los ámbitos en los que el cara a cara sea desplazado por la aparición de un tercero, es decir, a todos aquellos campos en los que la ética, debido a la naturaleza misma del dominio económico y del gozo, no sea el principio rector de la relación. El peso del control ético podría, por ejemplo, convertir la distorsión "política" de carácter partidista en una praxis auténticamente dirigida hacia el beneficio de la polis y, de esta manera, romper con el abismo

14 Basado en Descartes (2011a), pero distanciándose de él en su “aplicación ética” (Lévinas, 1987a).

15 Tanto la guerra como la política no dejan de ser una expresión más del proceso alimenticio de incorporación de lo Otro en mí. Los dos fenómenos son una manifestación de la fuerza y voluntad de imposición del Mismo ejercidas sobre lo Otro. 
establecido por este tipo de prácticas entre ética, política y legalidad, en la que priman a todas luces los intereses particulares de grupos específicos de poder en detrimento de quien debería ser en última instancia el fin primigenio de una verdadera acción política: el Otro.

Dicho control podría también otorgar a la justicia un carácter ético, ya resaltado desde Aristóteles (1995), y así minimizar los posibles efectos perversos de una legislación dirigida a la defensa de los intereses de un grupo particular. Es debido a esta separación entre ética, política y justicia, que, en muchos casos - en los cuales "la política" prepotentemente se pronuncia-, la ética se convierte en un simple aderezo de libre elección, que otorga un plus de dignidad a quien decide tenerla en cuenta, pero no resta nada a quien decide pasarla por alto, pues es considerada como un contenido particular sin carácter incluyente para la actividad "política". Mientras Lévinas (1987a) confiere a la ética un valor absoluto como "experiencia" primigenia en la que se constituye la propia "subjetividad" del Mismo, la concepción común - política y legal- considera que esta no es más que un contenido relativo y subordinado.

El control ético, ya indicado, podría también moderar, por ejemplo, el excesivo interés del gozo que prima en las relaciones económicas fundadas en la competencia y la producción generadora de ganancia, y en la educación centrada exclusivamente en la preparación de capital humano propicio al interés económico del momento.

Lo fundamental en esta descripción de la primacía del gozo sobre la ética es el llamado de atención acerca de tres fenómenos que convergen en una estructural co-pertenencia: (a) el desplazamiento del Otro debido a la primacía de la mirada del Mismo; (b) la concepción del ente en su totalidad como simple alimento, y de la experiencia de "ser en el mundo" como mera economía; y, en consecuencia, (c) la primacía del ansia de poder, y con ello de la guerra y la violencia inherente a todo proceso de incorporación de lo Otro en mí. Este es el contexto que permite entender el llamado levinasiano hacia un control ético de las formas sociales en todas sus expresiones (Lévinas, 1991).

Se hace evidente, entonces, que el ámbito ético se diferencia también del ámbito social y de sus instituciones, en el sentido de una cierta preeminencia de la relación ética sobre todos los otros tipos de relación humana: esta es la razón por la cual Lévinas pretende entender el mundo social surgido con la aparición de un tercero, a partir de la relación primigenia del cara a cara ético, limitado por el poder de las instituciones, que aun siendo indispensables para el sostenimiento de la convivencia humana, tienen una naturaleza derivada de lo intersubjetivo en su sentido más originario. Este es el fundamento de la necesidad del control ético sobre las instituciones creadas por el hombre. Economía, "política" y educación, entre otras actividades humanas en las que la ética del rostro es desplazada por los principios del pragmatismo y el utilitarismo - tomados como modos instrumentales de considerar el mundo como objeto de alimentación (Horkheimer, 1973)—, pueden ser reguladas desde la asunción ética del Otro en la responsabilidad.

Queda claro, por lo tanto, el significado de cada uno de los ámbitos posibles de la relación del hombre con lo Otro - el dominio del gozo que pretende alimentarse del mundo, la ética fundada en la responsabilidad asumida como una orden sin palabras y el ámbito de las instituciones reguladoras de la praxis social-. Quedan asimismo bosquejadas las 
bases filosóficas necesarias para pensar en las posibles consecuencias de la prevalencia de un ámbito sobre el otro en la experiencia compartida de lo humano: el mundo concebido como alimento, la relación "intersubjetiva" asimétrica guiada por el carácter trascendente del Otro considerado como maestro (Lévinas, 1987a) ${ }^{16}$, y el predominio del legalismo y la instrumentalización de la economía y la educación, cuando estas anteponen lo relativo de las instituciones mediadas por intereses particulares a lo absoluto de la revelación del Otro (Lévinas, 1987a) ${ }^{17}$.

Es de resaltar, en consecuencia, que en cualquier caso la ética del encuentro cara a cara permanecerá, "ontológicamente" pensada, como un ámbito más originario que la ley, la política — aun la aristotélica: la ética de la virtud ${ }^{18}$ —, la economía, e incluso la educación en su aspecto meramente institucional. La ética, más allá de la legalidad y de la administración del Estado, es "superación" de la política y del sostenimiento de las leyes para el poder y la guerra.

\section{"Derivaciones" para la educación}

Es posible plantear ahora la pregunta acerca de cuáles podrían ser las "derivaciones" del pensamiento de Lévinas en la educación. Esta pregunta implica la superación de dos interrogantes comúnmente planteados a la hora de pensar la relación entre ética y educación - ¿cómo es posible enseñar adecuadamente la ética? y ¿cuál es el rol de la ética en la educación y en la pedagogía?-, para llegar a cuestionamientos ligados con la perspectiva levinasiana: ¿qué nos trae como "enseñanza" la revelación del Otro? y ¿cuál es el "rol formativo" del Otro en mí?

En este contexto, no es descabellado sostener que una especial atención sobre los ámbitos tratados por Lévinas - el del gozo, el del Deseo y el que corresponde a la presencia de un tercero- puede concluir en la concepción de dos metáforas referidas a dos tipos diversos de educación: la educación como instrucción y la educación como formación en la apertura hacia el Otro.

Basados en el ámbito del gozo, es posible centrar la atención en un tipo de educación caracterizado por la instrucción, exclusiva o preponderantemente, profesionalizante. Este modelo educativo tiene como objetivo básico la capacitación de mano de obra calificada que sustente al sistema económico-político imperante. Es el tipo de educación hoy en día conocido como educación en competencias (Krautz, 2010, 2015), que propende no solamente al fortalecimiento de las habilidades técnicas y procedimentales necesarias para cada uno de los campos en que está compartimentalizado el saber especializado, sino que busca una buena preparación para el mundo laboral (Brandt, 2011).

16 El Otro es considerado por Lévinas como maestro (1987a), no en aquel sentido que implica un "discípulo", "un estudiante" (Critchley, 2005), sino en términos de quien ya enseña con su presencia (1987a). No se trata de un simple mediador entre el conocimiento y el discente, sino de quien "enseña" la trascendencia, y con ello el carácter del Infinito, que es la expresión misma de la altura "me juzga" (Lévinas, 1987a). El maestro es quien me abre a mi propia subjetividad en la responsabilidad (Lévinas, 1987a). Tal es la esencia del "magisterio", que Lévinas identificará la justicia con el reconocimiento del maestro en el rostro del Otro (1987a).

17 En El tiempo y el Otro (1993a), se reitera: (1) el uso de tres conceptos recurrentes en Lévinas para señalar la "forma" como se expresa el rostro, resaltando con ello el sentido de la carencia: de esposo — la viuda—, de padre —el huérfano- y de patria —el extranjero-; y (2) la consideración del Mismo como poder (Lévinas, 2000).

18 A pesar de su esencia social y política, la ética de la virtud nacida con Aristóteles está arraigada en la perspectiva del Mismo, quien en tanto origen de la acción moral proyecta y provee, en este caso, a la polis con su sano carácter de justo medio. 
Sin dejar de lado el sentido de la metáfora levinasiana al respecto, se puede afirmar que una educación centrada en las competencias necesarias para el cumplimiento de las exigencias del mundo laboral es una educación organizada para la alimentación y para el gozo del mundo, considerado como un simple ente dispuesto al uso, a la apropiación y explotación: esta es la experiencia que está en la base de la sociedad de consumo, de la razón centrada en el vínculo de medios y fines (Horkheimer, 1973), del dominio del pensamiento calculador sobre toda otra forma posible de despliegue del pensar y de la destrucción del planeta en todas sus vertientes ${ }^{19}$, al considerar el mundo como simple reserva dispuesta para el uso (Heidegger, 1960, 1994, 2006).

Con esta descripción se está pensando, por una parte, en el tipo de educación que forja el dominio totalizador del pensar calculador ${ }^{20}, y$, por otra parte, en aquel proceso educativo formal que expresa el triunfo de la experiencia del mundo como objeto de consumo sobre la experiencia de la revelación del Otro en tanto inapropiable: no concebido como alimento asequible al gozo. Este modo de educar, y su objetivo de dominar el mundo natural y humano para consumirlo apropiándose de él, puede ser entendido también, a modo de ejemplo, a partir del concepto de "imperativo de la habilidad", tratado por Kant (2012): toda acción determinada por el objetivo de alcanzar eficientemente un fin "técnico" particular, en la que se expresa la separación entre una acción de alta habilidad instrumental y la exigencia moral inherente a la conversión de una máxima de la acción en ley universal.

La cuestión aquí no es si el fin es razonable y bueno, sino solamente lo que uno ha de hacer para conseguirlo. Las prescripciones dadas por el médico para hacer sanar [...] a su paciente y las dadas por un envenenador para matar infaliblemente a ese mismo hombre son de idéntico valor, en tanto que cada cual sirve para realizar cabalmente su propósito. (Kant, 2012, p. 116)

La habilidad técnica necesaria para alcanzar un fin determinado puede ser, entonces, exactamente la misma en dos casos diferentes, a pesar de que las dos acciones no coincidan en el tipo de meta propuesta ni en el objetivo moral implícito en cada una de ellas: la destreza con que es llevada a cabo cada acción es valorada positivamente solo si logra el cumplimiento de la meta buscada. Asumidas en su pureza, la habilidad técnica y la acción centrada exclusivamente en el logro de un objetivo no contemplan en sí mismas la valoración previa de las consecuencias morales de la acción.

Otra cosa sucede cuando la acción pasa por el filtro del peritaje ético. Con la óptica de este filtro, la acción instrumental con arreglo a fines y la primacía de la habilidad pierden su valor absoluto y son valoradas a partir del análisis de sus consecuencias éticas: tener la habilidad en el uso del bisturí durante una cirugía, ya no es lo mismo que poseer esta destreza con el fin de asesinar a un ser humano. La acción es valorada ahora por sus connotaciones éticas: en el primer caso, se trata de un médico cirujano que salva vidas; mientras que, en el segundo caso, no podemos pensar más que en un asesino, aunque tenga como profesión

19 Fenómeno en el que convergen, a pesar de sus diferencias, la concepción del ente como simple reserva - Heidegger-, del mundo natural y humano como medio de un fin - Horkheimer-, y de lo Otro visto exclusivamente como alimento —Lévinas-. Competencias, emprendimiento, habilidades... son algunos de los conceptos capitales de esta concepción educativa propia de las sociedades de la producción.

20 Se trata de una educación que fomenta la racionalidad que busca el dominio del mundo natural y humano, y que, por ello, concibe lo ente como un simple medio para el logro de los fines establecidos. Puede hablarse entonces de una educación para el trabajo y el usufructo del mundo - “educación para el gozo”-, y de otra educación para la reflexión y la crítica. 
la medicina. La habilidad no puede ser valorada, entonces, en términos exclusivamente técnicos, sino que es definida en relación con un componente ético que va más allá de ella misma.

Este tipo de educación concebida como proceso de capacitación del hombre para la producción, con el objetivo de alcanzar el bienestar material, caracteriza a las sociedades contemporáneas, determinadas por el ansia de dominar el mundo para ponerlo a su disposición. Esta es la estructura ontológica que corresponde a la descripción levinasiana del ámbito del gozo en tanto despliegue exclusivo del ansia de alimentación, de "la transmutación de lo Otro en Mismo [...] [en] mi energía, mi fuerza, yo. Todo gozo, en este sentido, es alimentación" (Lévinas, 1987a, p. 130)²1.

En el contexto de una educación para el trabajo, y con ello para la alimentación y el gozo, la ética es concebida como un simple aderezo de la enseñanza de las ciencias y las técnicas facilitadoras del dominio sobre la naturaleza natural y sobre la naturaleza humana, cuando no como un simple conjunto de normas del quehacer profesional, y como una especie de adorno en el proceso de adquisición de la habilidad y los conocimientos que se constituyen en objeto del adiestramiento profesional. En el marco de la educación profesionalizante que caracteriza al sistema educativo actual (Brandt, 2011), la ética se convierte en un simple acompañante de la educación.

Pero de la misma manera que la educación no debe estar solamente fundada en el plano económico del gozo y del consumo, de la productividad y de las habilidades necesarias para el impulso incontenible del desarrollo económico e industrial, tampoco debe estar centrada en la defensa de un sistema político determinado. Su objetivo final deberá ser sensibilizar al hombre en la responsabilidad para con el Otro inalienable, independientemente del modo en que la sociedad se organice política y económicamente.

La ética del Otro no puede limitarse, por lo tanto, a la formación de un hombre "en" y "para" un sistema político-económico o sociocultural particular, ya que ella es más originaria y primigenia que todo tipo de aparición de un tercero: es la auténtica condición ideal de posibilidad de la aparición en escena de un tercero. La razón fundamental es que todo sistema político, económico, legal... es en esencia relativo a una época, a un contexto, a una situación del hombre en la historia, mientras que el carácter de la responsabilidad para con el Otro es un "absoluto" que no depende de un momento histórico particular ni de una decisión de la voluntad humana: se configura, por el contrario, como la condición de posibilidad misma de la constitución del yo y de la subjetividad del Mismo. Es en este sentido que no es relativa y, por ende, es primigenia y más originaria que toda forma posible de aparición de un tercero.

Más allá de un simple adiestramiento especializado, en consecuencia, la educación puede encontrar su verdadero sentido en la "sensibilización" de cada hombre hacia la expresión del Otro, revelado como extranjero - das Frende: lo extraño, lo que me es ajeno, lo totalmente Otro que no puedo apropiar- y, en tal sentido, como trascendencia. Solo así el imperativo de la habilidad tendría significado y sería concebido como un instrumento más al servicio de la praxis moral del hombre para el hombre. La ética dejaría de ser un simple aderezo en

21 La "alimentación” se expresa también en todo proceso de conocimiento como forma de incorporar el mundo en mí, como sucede, por ejemplo, a través de la representación, la interpretación y la percepción (Lévinas, 1993a). 
la educación y se convertiría en el sentido de esta, al relegar a un segundo plano el rasgo deontológico y axiológico con el que es determinada en muchas de sus aplicaciones en el ámbito educativo.

El ideal de una praxis ética que prime sobre la política y la economía — sin llegar a negarlas, obviamente- y que atraviese el amplio espectro de lo que hoy entendemos por educación sería la base para el desarrollo de todo sistema político y económico que fije la mirada en el Otro, para que permanezcamos en nuestra propia "esencia" de hombres. Por ello, el sentido último de la educación no estaría en los requerimientos siempre relativos de un sistema político y económico particular, sino en la exigencia ética de "absoluta" responsabilidad para con el Otro, no matizada por contexto social, político, cultural o económico alguno, ya que carece de una determinación específica que configure la definición de una figura para el rostro. Libre de una forma que permita representarlo desde parámetros relativos a las creaciones ideológicas humanas, el Otro se constituye en el sentido mismo de la labor educativa en tanto formación. La ética deja de ser un contenido más entre otros muchos, para convertirse en el eje que atraviesa toda la actividad pedagógica. Gracias a este nuevo sentido de la educación, el imperativo de la habilidad, y con ello el adiestramiento para el trabajo, quedarían subordinados y juzgados por la ética. Esta preeminencia ética conduciría hacia la primacía del hombre sobre todo interés instrumental, proclive a la magnificación del desarrollo material y a la sumisión del hombre al mundo del trabajo y de la productividad sin miramientos de carácter moral. El nuevo sentido de la educación se configuraría, entonces, como expresión de la liberación de lo auténticamente humano en la responsabilidad para con el Otro, y con ello en la sujeción del Mismo al pobre y al extranjero, sinónimos de la voz de la humanidad entera que clama desde el rostro del Otro en tanto trascendencia.

\section{Referencias}

Aristóteles. (1990). Metafísica. Gredos.

Aristóteles. (1995). Ética nicomáquea / Ética eudemia. Gredos.

Bernasconi, R., Critchley, S., \& Peperzak, A. (Eds.). (1996). Emmanuel Lévinas: Basic Philosophical Writings. Indiana University Press.

Brandt, R. (2011). Wozu noch Universitäten. Ein Essay. Meiner.

Critchley, S. (2005). Introducción a Lévinas. En E. Lévinas, Difícil libertad. Ensayos sobre el judaísmo. (pp. 11-39). Lilmod.

Descartes, R. (2011a). Meditaciones metafísicas. Seguidas de las objeciones y respuestas. Gredos.

Descartes, R. (2011b). Discurso del método. Gredos.

Heidegger, M. (1960). Serenidad. Eco. Revista de la cultura de occidente, 1(4), 337-352.

Heidegger, M. (1994). La pregunta por la técnica. En Conferencias y artículos. (pp. 9-37) Ediciones del Serbal.

Heidegger, M. (2006). Carta sobre el humanismo. Alianza.

Horkheimer, M. (1973). Crítica de la razón instrumental. Sur. 
Jäger, W. (2002). Paideia. Los ideales de la cultura griega. FCE.

Jaramillo, D., Jaramillo, L., \& Murcia, N. (2018). Acogida y proximidad: Algunos aportes de Emmanuel Lévinas a la Educación. Revista actualidades investigativas en educación, 18(1), 1-16. http://dx.doi.org/10.15517/aie.v18i1.31771

Kant, I. (2012). Fundamentación para una metafísica de las costumbres. Alianza.

Krautz, J. (2010). Die Kompetenz des Homo oeconomicus. Viertelsjahrsschrift für wissenschaftliche Pädagogik, (3), 332-345. https://doi.org/10.30965/25890581-08603005

Krautz, J. (2015). Kompetenzen machen Unmündig. Streitschriften zur Bildung (Heft 1). GEW.

Lévinas, E. (1987a). Totalidad e infinito. Sígueme.

Lévinas, E. (1987b). De otro modo que ser, o más allá de la esencia. Sígueme.

Lévinas, E. (1991). Ética e infinito. Visor.

Lévinas, E. (1993a). El tiempo y el Otro. Paidós.

Lévinas, E. (1993b). Entre nosotros. Ensayos para pensar en otro. Pre-textos.

Lévinas. E. (2000). De la existencia al existente. Arena Libros.

Lévinas, E. (2006a). Ética como filosofía primera. A parte rei. Revista de filosofía, (43), 1120.

Lévinas, E. (2006b). Los imprevistos de la historia. Sígueme.

Lévinas, E. (2009). Humanismo del otro hombre. Siglo XXI.

Lévinas, E. (2017). La teoría fenomenológica de la intuición. Sígueme.

Mínguez, R. (2010). La escuela hoy en la encrucijada. Hacia otra educación desde la ética de E. Lévinas. Teoría de la educación. Revista interuniversitaria, 22(2), 43-61. http://dx.doi. org/10.14201/ted.8294

Mosès, S. (2004). Más allá de la guerra. Tres estudios sobre Lévinas. Riopiedras.

Rocha, A. (2014). Totalitarismus des Seins? Die Ethik bei Lévinas als Kritik am Heideggers Denken. En I. Römer (Ed.). Affektivität und Ethik bei Kant und in der Phänomenologie. (pp. 241-252). Walter de Gruyter.

Romero, E., \& Pérez, C. (2012). Aproximación al concepto de responsabilidad en Lévinas: implicaciones educativas. Bordón. Revista de Pedagogía, 64(4), 99-110. 